\title{
Ocupação urbana, moradia e psicologia: uma experiência grupo-operativa com famílias
}

\author{
Urban occupation, housing and psychology: an \\ operative-group experience with families
}

\section{Guilherme Faria Ribeiro', Lucas Rossato ${ }^{2}$, Tales Vilela Santeiro ${ }^{3}$ e Tatiana Machiavelli Carmo Souza ${ }^{4}$}

Resumo: O objetivo deste estudo é apresentar relato de uma experiência de atividade grupooperativa realizada com famílias de uma ocupação urbana assistidas por um Centro de Referência e Assistência Social de um município do interior de Minas Gerais. Participaram da atividade 32 pessoas divididas em dois grupos operativos, coordenados por um psicólogo que mediou as interlocuções. A experiência vivenciada aponta que a ausência de moradia e submissão das pessoas à situação de assentamento caracterizam-se como problemas macrossociais, interligados por uma série de outras questões de ordem social, política, econômica e histórica que incidem na qualidade de vida, nas condições de saúde da população, na exposição à situações de risco e, consequentemente, no desenvolvimento humano de forma geral. Os grupos mostraram-se importantes ferramentas para expressar sentimentos e construir elaborações em relação às vivências no assentamento e os problemas sociais enfrentados no processo de ocupação. As atividades de acolhimento desenvolvidas pela psicologia junto a populações vulneráveis demostram a importância da inserção desses profissionais nas equipes multidisciplinares dos mecanismos de atenção social governamentais.

Palavras-chave: Vulnerabilidade social; Processos grupais; Habitação.

\begin{abstract}
The aim of this study is to present an account of an experience of group-operative activity carried out with families of an urban occupation assisted by a Reference and Social Assistance Center in a municipality in the interior of Minas Gerais. 32 people participated in the activity, divided into two operational groups, coordinated by a psychologist who mediated the interlocutions. The lived experience points out that the absence of housing and submission
\end{abstract}

\footnotetext{
1 Psicólogo pela Faculdade Pitágoras de Uberlândia. Mestre em Psicologia pela Universidade Federal do Triângulo Mineiro (UFTM). E-mail: guilhermefariaribeiro@hotmail.com

2 Psicólogo pela Universidade Federal de Goiás - Regional Jataí (UFG). Mestre em Psicologia pela Universidade Federal do Triângulo Mineiro (UFTM). Doutorando em Enfermagem Psiquiátrica na Escola de Enfermagem de Ribeirão Preto da Universidade de São Paulo (EERP/USP). E-mail: lucas_2007_rossato@yahoo.com.br

3 Psicólogo pela Universidade de Franca, Mestre em Psicologia Clínica e Doutor em Psicologia como Profissão e Ciência, pela Pontifícia Universidade Católica de Campinas. Professor associado pela Departamento de Psicologia da Universidade Federal do Triângulo Mineiro (UFTM) e Professor Permanente do Programa de Pós-Graduação em Psicologia da UFTM. E-mail: talesanteiro@hotmail.com

4 Psicóloga pela Universidade Federal de Uberlândia. Mestra e Doutora em Serviço Social pela Universidade do Estado de São Paulo (UNESP-Franca). Professora associada da Universidade Federal de Catalão (UFCAT) e Professora Colaboradora do Programa de Pós-Graduação em Psicologia da UFTM. E:mail: tatimachiavelli@yahoo.com.br
} 
of people to the settlement situation are characterized as macro-social problems, interconnected by a series of other social, political, economic and historical issues that affect the quality of life, the conditions of population health, exposure to risk situations and, consequently, human development in general. The groups proved to be important tools to express feelings and build elaborations regarding the

\section{Introdução}

Oacesso à moradia constitui-se em importante questão social da atualidade dadas desigualdades psicossociais, políticas, econômicas e históricas envolvidas nesse direito. As dificuldades de acesso à habitação tratam-se de problema social complexo que interferenas condições devida das pessoas em diversas localidades do mundo, mobilizando a criação de políticas públicas com objetivo de atender a demandas urgentes que se amplificam no atual contexto (Desmond \& Gershenson, 2016; Mishra \& Mohanty, 2017; Nascimento Neto \& Arreortua, 2019).

Buscando transcender a concepção de moradia meramente como espaço de abrigo, questões respectivas envolvem olhar para os múltiplos significados atribuídos a este local, em nível intrassubjetivo e social. Quando se fala em habitação, deve-se levar em conta não apenas o local onde se habita, a estrutura física estabelecida por uma pessoa e/ou família, mas sim, toda a rede que circunda as pessoas de determinada habitação física, o que inclui os aspectos de integraçãa desse espaço no contexto urbano, como a comunidade, o bairro, os locais de serviços, a rede de saúde e de assistência social, os comércios, as igrejas (Pasternak, 2016).

№ Brasil, os problemas de moradia são parte da constituição sócio-histórica do país. A análise das políticas públicas de habitação mostra que somente nos anos de 1960 o governo brasileiro compôs a primeira política social estruturada para o enfrentamento do problema habitacional. Naquele momento, o Sistema Financeiro da Habitação e o Banco Nacional da Habitação foram criados, atuando durante 22 anos e sendo extintos em 1986. Apenas nos anos 2000 houve retomada de ações do governo em relação a essa pauta (Rodrigues \& Moreira, 2017).

Neste contexto, movimentos sociais como o Movimento de Luta Social por Moradia, criado em 1990, e o Movimento dos Trabalhadores Sem Teto, criado em 1997, têm importante papel na luta por políticas públicas que assegurem o direito à moradia, contrários aos modelos hegemônicos neoliberais (Nascimento, 2016). A moradia tem se constituído em direito negado a parcela significativa da população, especialmente, a mulheres, a negros/as, a indígenas, a pessoas em situação de pobreza. Essa característica resguarda aspectos históricos e hereditários ligados à manutenção de interesses e privilégios das elites (Conselho Regional de Psicologia de São Paulo, 2019).

Considerando os impactos da falta de habitação na vida humana, a psicologia tem papel relevante a desempenhar nesse panorama, principalmente pelo amplo processo de inserção dos/as profissionais psicólogos/as nos equipamentos atenção social, a exemplo do Centro de Referência e Assistência Social (CRAS), instituído pela Política Nacional de Assistência Social (PNAS). 0 CRAS tem como finalidade o fortalecimento da função protetiva das famílias, a fim de prevenir a ruptura de seus vínculos, promover seu acesso a direitos $\mathrm{e}$ contribuir para melhoria da qualidade de vida (Brasil, 2005). experiences in the settlement and the social problems faced in the occupation process. The reception activities carried out by psychology with vulnerable populations demonstrate the importance of including these professionals in the multidisciplinary teams of the governmental social care mechanisms.

\section{Keywords: Social vulnerability; Group processes; Housing.}

Entre as diversas práticas profissionais em psicologia no âmbito das políticas de assistência social, evidencia-se a atuação junto aos aspectos psicossociais envolvidos nos problemas de moradia. Pensar a interface psicologia e moradia implica em problematizar os sentidos do viver, as relações de pertencimento, a produção de subjetividades negadas e o movimento de desfiliação social que ocasiona a ruptura do tecido social e de relações de solidariedade.

Os/as psicólogos/as devem cumprir os aspectos éticos da profissão e assumir os princípios fundamentais da atuação em intersecção entre moradia e habitação, pois, morar significa viver e viver remete ao direito básico da dignidade humana. À psicologia cabe oferecer acolhimento às pessoas, apoiar a luta dos/as trabalhadores/as pelo direito à moradia, fomentando processos grupais e individuais de emancipação (Conselho Regional de Psicologia de São Paulo, 2019).

A inserção da Psicologia nos debates sobre acesso à moradia implica no fortalecimento das experiências comunitárias em direção ao enfrentamento das formas de exclusão social e garantia de justiça. Nesse viés, Euzébios Filho (2019) aponta que os pilares ético-políticos acerca do direito à moradia são a humanização (não há humanização sem experiência coletiva), a autonomia (possibilidade para a autorrealização) e a dignidade humana.

As lutas para conseguir um espaço digno para morar, a residência em locais inadequados e o próprio ambiente onde a pessoa habita interferem nos aspectos da saúde física e mental da populaçã̃o, têm impacto nas condições globais de desenvolvimento humano e sociocultural (Baker et al., 2020; Clark \& Kearns, 2012; Rollings, Wells, Evans, Bednarz, \& Yang, 2017). Considerando as questões levantadas sobre 0 acesso à moradia, 0 breve resgate das políticas de enfrentamento como garantia de direitos, principalmente à população de baixa renda e o papel da psicologia enquanto ciência e profissão que atua em contextos sociais onde essa problemática emerge, o objetivo deste artigo é apresentar relato de experiência de intervenção grupal com famílias que viviam em um assentamento em um município de Minas Gerais.

\section{Método}

Trata-se de um relato de experiência de intervenção grupal, realizada com famílias atendidas em um CRAS, que viviam em uma região periférica de uma cidade do interior de Minas Gerais. 0 município em questão possui aproximadamente 8.000 habitantes e tem como economia principal a agropecuária, em especial a criação de gado e sucroalcooleira, sendo que as lavouras de cana-de-açúcar cobrem quase toda a área territorial rural da cidade.

0 Departamento de Assistência Social da cidade conta com dois CRAS, cujas equipes são formadas por psicólogo, assistente social, terapeuta 
ocupacional e orientador social, e oferece atendimento a todas as famílias referenciadas, independentemente de faixas etárias. Com a demanda dos serviços das unidades dos CRAS, uma das formas de atendimento oferecido a esta população é o atendimento psicossocial, por meio de atividades grupais.

Durante o trabalho realizado pela equipe profissional do CRAS nos atendimentos, visitas domiciliares e buscas ativas no território, observou-se que havia grupos populacionais vivendo de forma precária, em barracos de lona, em partes periféricas da cidade. Eles não tinham acesso à energia elétrica, à água canalizada, além de terem precárias condições de higiene, alimentação, cuidados com a saúde, entre outros direitos lesados. Crianças brincando e nadando em lugares de água parada e lama, rodeadas de animais doentes e lixo entulhado perto dos barracos também foram facetas observadas.

A partir dos atendimentos notou-se que as famílias sofriam, ainda, formas de violência e preconceitos: não tinham acesso a informações importantes sobre seus direitos, principalmente em relação à moradia e a outros benefícios sociais. Somado a isto, havia baixo grau de instrução educacional. Outro aspecto observado eram as famílias extensas, compostas por muitos filhos/as, com presença de idosos/as. 0 tempo de ocupação do território pelas famílias girava em torno de 12 meses.

Partindo desses aspectos, grupos psicossociais foram pensados e criados para problematizar as vulnerabilidades vivenciadas. Cerca de 50 famílias que se encontravam na ocupação foram convidadas para integrar as atividades.

Um psicólogo - o primeiro autor desse relato - conduziu o grupo e, dispositivos como vídeo e uma pergunta disparadora foram utilizados para dialogar sobre a realidade dos/as participantes. Dois grupos foram realizados, um no período matutino e outro no vespertino, em um dia, com horários preestabelecidos pelo coordenador, sendo que as famílias podiam escolher 0 período que gostariam de participar. Como instrumento no desenvolvimento das atividades foram utilizados dispositivos grupais, com inspiração no modelo dos Grupos Operativos de Pichon-Rivière (1983/2009).

Os Grupos operativos têm objetivos, problemas, recursos e conflitos que devem ser estudados e considerados pelo próprio grupo, à medida que surgem na dinâmica grupal, como emergentes do trabalho que se desenvolve conjuntamente (Bleger, 1979/2007; Castanho, 2012; Pichon-Rivière, 1983/2009). Nessa proposta, os trabalhos sobre uma determinada tarefa se articulam para construção de um clima propício a processos de aprendizagem coletiva (Pichon-Rivière, 1983/2009).

A tarefa é, assim, o momento em que o grupo consegue elaborar seus medos e suas vulnerabilidades, rompendo com estereótipos e preconceitos. $E$ por meio dela que os/as participantes se comunicam, aprendem e estabelecem (Pichon-Rivière, 1983/2009). Respeitar os emergentes grupais é, segundo Bleger (1979/2007), uma regra de ouro, pois, o trabalho ocorrerá através das informações que o grupo atualiza a cada momento.

Assim, na atividade aqui descrita, os grupos foram desenvolvidos na sede do CRAS, no ano de 2019, com os usuários do território em questão e a tarefa grupal (tarefa explícita) proposta inicialmente pelo coordenador era discutir/problematizar as experiências quanto ao acesso a moradia: como é para vocês morarem em uma ocupação? E quais dificuldades enfrentam. Respectivamente, 15 pessoas no período matutino e 17 no vespertino compareceram; cada encontro teve duração média de 60 minutos.

\section{Resultados e Discussão}

No grupo em questão, os diálogos se iniciaram com queixas sobre a precariedade das condições materiais de vida que as pessoas vivenciavam: falta de alimentos, água, luz, higiene pessoal, segurança e, especialmente, existência de moradias precárias. Esse tipo de relato, muito tocante no modo como ocorria e reverberava entre os/as presentes, acentuava que tratar de problemas de moradia evidencia como as pessoas afetam e são afetadas emocionalmente pelo contexto precário, pelo impedimento ao exercício da cidadania e por outros fatores de risco (Fernandes, 2016). Naturalmente, 0 coordenador das atividades não ficava imune aos efeitos emocionais do que era relatado. Neste sentido, as intervenções do coordenador não operavam a partir de suas impressões particulares, mas elas emergiam de uma construção de todos, tais intervenções só fazem sentido se compreendidas como parte do contexto grupal (Castanho, 2017).

Além disso, pela dinâmica dos grupos operativos deve-se considerar que o próprio grupo trabalha a partir de individualidades. Cada pessoa apresenta-se com sua individualidade, sua história pessoal, verticalidade e com o desenvolvimento das atividades grupais espera-se a construção de um esquema conceitual, referencial e operativo de caráter dialético (Pichon-Rivière, 1983/2009), em um movimento que caminha para a horizontalidade das experiências. No processo de desenvolvimento das atividades grupais, por meio da dialética entre os/as participantes, conteúdos de ordem individual passam para a ordem da coletividade. Esse movimento contribuía na dinâmica de funcionamento grupal e na construção da coesão entre os membros presentes.

A partir de inferências do coordenador, relatos sobre a falta de moradia trouxe à tona reflexões de que ela é agudizada por ser (re)produtora de outras questões sociais. No caso dos/das participantes, também se percebeu que a falta de moradia digna estava vinculada à precarização dos recursos financeiros vivida. Alguns deles possuíam renda inferior ao salário mínimo, trabalhavam em serviços gerais, a maior parte em fazendas e, além de não serem registrados formalmente no trabalho, eram reiteradamente ameaçados de serem demitidos pelos patrões. Isso tudo, em muitas situações os remetia a estarem em ambientes precários, totalmente sem condições adequadas para o desenvolvimento enquanto cidadãos. Percebia-se que as narrativas dos/das participantes incluíam fatores debatidos na literatura: os riscos relacionados ao lugar de moradia incluíam a precariedade da oferta de instituições e serviços públicos, a falta de disponibilidade dos espaços destinados ao lazer, às relações de vizinhança e a proximidade da localização dos pontos de venda controlados pelo tráfico de drogas, riscos do trabalho infantil e da exploração sexual e da prostituição de crianças (Fonseca, Sena, Santos, Dias, \& Costa, 2013).

A exposição das pessoas a contextos de extrema precariedade socioeconômica colocava-os em uma condição de humilhação, impotência e adoecimentos. Estudos têm apontado que pessoas que passam por dificuldade no acesso à moradia possuem piores níveis de saúde mental, em comparação àquelas que não passam por situações semelhantes (Baker et al., 2017; Baker, Lester, Mason, \& Bentley, 2020). Viver com problemas de moradia no passado também está associado a problemas de saúde mental no presente e viver em moradias persistentemente precárias prejudica a saúde mental das pessoas (Pevalin, Reeves, Baker, \& Bentley, 2017).

Diante de todas as cadeias associativas dos/das participantes, percebeu-se vários porta-vozes no grupo. De acordo com Pichon-Rivière (1983/2009), o porta-v0z é aquele/a participante que se espera denúncias a respeito de 
necessidades, ansiedades e angústias, é um papel fundamental para elaboração da tarefa. É dele a função de falar não só em nome próprio, mas do grupo como um todo, mesmo que ele e o grupo não tenham consciência sobre isso.

Assim, todas as denúncias, dificuldades e vulnerabilidades tratadas pelos porta-vozes diziam de todos. Nos momentos que o coordenador percebia movimentos de porta-vozes, ele intervia, buscando auxiliar o grupo na integração do sentir, do pensar e do agir para 0 adentramento na tarefa (Pichon-Rivière, 1983/2009). As intervenções grupais, portanto, buscaram assumir uma posição de não patologização dos processos psicossociais, bem como a promoção de ações que possibilitassem a autonomia e o enfrentamento crítico e coletivo frente aos processos de desigualdade e exclusão social. Desta forma, notava-se avanços no processo dos grupos quando os/ as próprios/as participantes demonstravam "descobrir" aspectos novos da realidade que os/as circundava, Ainda que apenas uma sessão tenha sido proposta naquele momento, graus de operatividade grupal eram perceptíveis.

As pessoas que participaram das intervenções mencionaram que não se reconheciam como cidadãos/ãs de direito, afirmaram que estavam abandonamos/as, marginalizados/as e ignorados/as. Foi relatado que antes da realização dos grupos, participaram de um manifesto na porta da prefeitura, reivindicando moradia, alimento, vida digna para si e seus/uas filhos/as. Essa forma de organização popular é reveladora das potencialidades daqueles/ as moradores/as em agirem coletivamente em prol de demandas também coletivas.

Nesse contexto, os movimentos sociais se configuram como legítimos e importantes para a luta de classes populares (Vasconcelos \& Sampaio, 2018). A ocupação e a autoconstrução de moradias também poderiam ser compreendidas como modalidades de ação coletiva a que recorrem os grupos vulnerabilizados, na ausência de um Estado de bem-estar social que thes garanta 0 direito à moradia (Tatagiba \& Teixeira, 2016).

Brigas por demarcações de terras e por melhor local para construir suas barracas eram relatos frequentes. Juntamente às disputas por melhor espaço, verificou-se histórias de ameaças de morte entre vizinhos/as, além de intimidação em ter a barraca roubada e ser expulso/a do local, caso houvesse discordâncias quanto ao pedaço de terra que Ihe foi cedido. Também foi relatado pelos/as moradores/as o barulho de disparos de tiros, que acreditavam serem dos/as proprietários/as do local.

Os sentimentos de medo de serem mortos/as e de terem seus barracos invadidos eram constantes. Além disso, os/as assentados/as vivenciavam reiteradas experiências de discriminação por parte de moradores/as da cidade, que os/as desrespeitavam, violentavam verbalmente e os/as subjugavam.

Para além dos membros dos grupos, os maus tratos se incidiam sobre seus/uas filhos/as. No contexto escolar, frequentemente eram notificados/ as e ameaçados/as de perderem a vaga no sistema de ensino, pois, a direção dizia que as crianças e os/as adolescentes chegavam sujos, com piolho e em precárias condições de higiene. A esse respeito, Vasconcelos e Sampaio (2018) debatem que moradores/as de ocupações urbanas costumam sofrer vários tipos de violência física, prisões, ameaças de morte, criminalização pela luta de terras, são associados/as a vagabundos/as e bandidos/as por outras pessoas da comunidade e, ainda, têm acesso negado aos direitos básicos, como educação e saúde.

Após todos os diálogos grupais terem se constituído (emergentes), percebeu-se que o grupo "esteve em tarefa", pois, percebeu-se falas de muita mobilização emocional e política sobre suas vivências tão atravessadas pela negligência, precarização, criminalização, preconceito e violência. No movimento grupal, os/as participantes puderam testemunhar possibilidades de lidar com suas fantasias, ansiedades, vulnerabilidades e medos, o que podia gerar possíveis elaborações sobre o que sentiam (Pichon-Rivière, 1983/2009). Deste modo, pôde-se constatar a tarefa sendo elaborada em seu aspecto dinâmico, tendo em vista que é por ela que cadeias associativas, emoções e conteúdos psíquicos se compunham e se opunham, de forma mútua (Castanho, 2017).

O grupo também foi assertivo em auxiliar na inserção dos/das participantes em programas governamentais, tais como: inclusão do Cadastro Único para recebimento de benefícios de transferência de renda tal qual o Bolsa Família, recebimento de benefícios eventuais como cesta básica, matrícula de crianças em creches e escolas, acesso a equipamentos de saúde, entre outros. Ademais, a promoção do grupo favoreceu a constatação de que as famílias inseridas no território poderiam ter nas figuras dos profissionais do CRAS um ponto de apoio psicossocial. Dessa forma intervenções futuras poderiam ocorrer de modo mais articulado, em consideração ao que as políticas públicas preveem e as realidades dos/das participantes e locais permitem.

Depois da realização dos grupos, houve conhecimento por parte do coordenador das atividades, de ordem judicial para remoção involuntária e desocupação de toda a área. Os barracos foram demolidos na frente dos assentados/as, que não tiveram tempo de tirar seus pertences, muita comoção tomou conta da equipe do CRAS e de toda população do entorno. Atos como estes demonstram a violência do Estado, o descaso do governo e ausência de políticas públicas, que, além de não garantirem de forma efetiva o direito à habitação, ainda provocava maiores sofrimentos, diante da remoção compulsória das famílias e da destruição de seus poucos pertences pessoais.

Cabe dizer que remoções involuntárias causam danos importantes nas pessoas, podem desencadear, de forma coletiva ou individual, sofrimentos, criam condições que impossibilitam a elaboração de perdas. Estes sofrimentos podem ser oriundos da perda do território, que possui um valor simbólico e afetivo, além de produzir formas de viver e conviver em sociedade, configurando um lugar de pertencimento (Vasconcelos \& Sampaio, 2018).

As experiências construídas e relatadas evidenciaram a importância da inserção da psicologia nos serviços de assistência social e nas políticas públicas estatais. Esta ciência, quando desenvolvida de forma crítica e com compromisso social, pode ocupar papel fundamental nos serviços de assistência social, promovendo ações que deem voz a uma população que muitas vezes é invisibilizada, tem seus direitos suprimidos e é obrigada a aceitar imposições sem ser consultada de suas necessidades básicas.

Sabe-se que, historicamente, a psicologia manteve-se por um longo período aliada a práticas conservadoras e elitistas, que não correspondiam à realidade da população atendida pelas políticas públicas (Senra \& Guzzo, 2012). Tais aspectos evocam o compromisso social do campo psicológico enquanto ciência e profissão ao longo dos anos, buscando a construção de práticas e a produção do conhecimento em consonância com a realidade e o contexto nacional (Euzébios Filho, 2019).

Promover espaços que busquem visibilizar as pautas por moradia e habitação, realizar uma escuta atenta às necessidades, reconhecer as demandas, e compreender as vivências diante de um contexto de exclusão e violência social, marcado por desigualdades de todas as naturezas, são orientações imprescindíveis aos profissionais de psicologia que atuam com o público aqui 
apresentado. Esse relato indica o reconhecimento da necessidade de promoção das ações coletivas e democráticas nas quais psicólogos/as possam contribuir cada vez mais para o reconhecimento dos/as cidadãos/ãs enquanto sujeitos/ as de direitos (Guareschi, 2017).

Para a formação e aprimoramento profissional, práticas como a descrita podem auxiliar na reflexão sobre a importância de discutir a dimensão política da práxis em psicologia. Fazê-lo é reconhecer que, no país, algumas necessidades sociais, econômicas e culturais básicas ainda assolam a população e determinam modos de vida e de subjetivação.

Além do exposto, discutir a necessidade de moradia nas práticas da psicologia demarca o olhar para um aspecto que ainda carece de debates e produções científicas que evidenciem o trabalho de psicólogas e psicólogos nesse cenário. Esses elementos podem servir de dispositivos para questionar o papel das políticas públicas de assistência social, refletir sobre os desafios que os profissionais vivenciam nesse espaço de trabalho, além de remeter a problematizações sobre alcances e limites da produção científica da psicologia brasileira.

0 grupo operativo, enquanto técnica de intervenção utilizada pelo psicólogo, mostrou-se uma ferramenta útil para facilitar a expressão de vozes das pessoas atendidas no CRAS. Como um dispositivo focado em uma tarefa, essa técnica permitiu direcionar os diálogos para pontos de urgência, a criação de um contexto de construções coletivas, por meio da cooperação e complementaridade, uma interação que busca desenvolver o senso de afiliação e pertença, a cooperação, a comunicação e a aprendizagem, semelhante ao descrito por Pichon-Rivière (1983/2009).

\section{Considerações finais}

A atual política de habitação no país foi conquistada a partir de lutas populares para efetivação do direito à moradia e à vida digna nas cidades, porém, parcela significativa da população não possui acesso. Esse relato é um ilustrativo do quanto esse cenário requer avanços no país. A despeito de argumentos e dispositivos sócio-políticos e econômicos institucionalizados contrários, a questão da moradia aqui contemplada é um problema insustentável, que (re)cria formas de violências.

A atuação da psicologia nas políticas de assistência social, em especial nos CRAS, configura-se como um caminho para possível obtenção de melhorias ao acesso e à efetivação de direitos sociais. Entretanto, também nesse âmbito, avanços são requeridos para que o trabalho do/a psicólogo/a não reafirme o lugar de negligência e vulnerabilidade que essa população se encontra.

As experiências trazidas pelos assentados foram enriquecedoras para compreender como são as vivências dos/das pessoas em situação de assentamento e que estão em busca por melhores condições de moradia. A experiência grupal empreendida evidenciou, além dos problemas referentes à moradia, outras demandas sociais atreladas a eles, tais como a precarização do trabalho, a dificuldade de higienização adequada, a falta de água, luz e alimentação, 0 não acesso a políticas de saúde e educação, entre outras.

Articuladores teóricos, como os pichonianos, podem ser úteis para se pensar e construir processos de aprendizado ocorridos em âmbitos grupais. Os emergentes grupais apresentados e dialogados denotaram o constante e incessante interjogo homem-mundo, salientando o quanto é impossível desmembrar as experiências dos participantes, do cenário socioeconômico e político do país e dos modos como minorias têm sido, insistentemente, (des)tratadas. 0 enlace do pensamento pichoniano a de outros autores contemporâneos que debatem políticas públicas de inclusão social mostrou-se e mostra-se imprescindível.

As potencialidades deste artigo estão na apresentação de uma temática pouco explorada na literatura científica nacional e que requer atenção, uma vez que as condições de moradia da população, a moradia inadequada ou a ausência de moradia constitui-se um problema social presente ainda na atualidade. Além disso, o profissional de Psicologia, por estar inserido nas equipes de atenção psicossocial dos municípios, irá se deparar com diversas demandas das pessoas atendidas nesses locais. Este profissional necessitará compreender temáticas como a exposta neste estudo, além de conduzir atendimentos embasados em métodos e técnicas cientificamente validados. Neste contexto, os atendimentos grupais fornecidos pela equipe de psicologia tem se mostrado um procedimento adequado para atender as demandas que emergem junto à população.

A psicologia ao se atentar para os movimentos sociais e históricos que perpassam a vida das pessoas, busca por meio de suas técnicas de trabalho resgatar um sujeito que muitas vezes se encontra fragilizado, não se reconhece como cidadão/ã de direito, não possui senso de coletividade e comunidade, não se reconhece enquanto pertencente ao espaço social e histórico que vive. Deste modo, cabe aos profissionais não apenas acolher as demandas que são postas, mas também auxiliarem no desenvolvimento da autonomia, transformando estas pessoas em sujeitos ativos, históricos, temporais, em interação com 0 ambiente e com a cultura em que vivem, consciente da dinâmica social que está envolvido.

Ações como a desenvolvida demonstram uma face da psicologia enquanto ciência e profissão que nas últimas décadas vem rompendo com estruturas e modos de trabalho. Esse movimento é parte de um processo histórico antigo de lutas para a implementação de uma psicologia que seja histórica, social, política, voltada para as reais necessidades da sociedade, que esteja atenta à cultura e particularidades de cada contexto, que valorize as diferenças e esteja atenta às singularidades.

Limites foram encontrados na implementação dos grupos operativos, como, por exemplo, ter tido apenas um coordenador mediando os dois grupos, em apenas uma sessão para cada. A presença de um observador poderia auxiliar nas reflexões pós-grupo e para anotar os principais movimentos grupais e a forma como havia adjudicação e assunção de papéis; entre outros aspectos.

\section{Referências}

Baker, E., et al. (2017). Is housing a health insult? International Journal of Environmental Research and Public Health, 14(6), 567. https://doi. org/10.3390/ijerph14060567

Baker, E., Lester, L., Mason, K., \& Bentley, R. (2020). Mental health and prolonged exposure to unaffordable housing: A longitudinal analysis. Social Psychiatry and Psychiatric Epidemiology, 1-7. https://doi.org/10.1007/ s00127-020-01849-1

Baker, E., Pham, N. T. A, Daniel, L., \& Bentley, R. (2020). New evidence on mental health and housing affordability in cities: A quantile regression approach. Cities, 96, 102455. https://doi.org/10.1016/j.cities.2019.102455 
Brasil. (2005). Ministério do Desenvolvimento Social e Combate à Fome. Guia de Orientação Técnica - SUAS n. 01 - Proteção Social Básica de Assistência Social. Brasília: Autor.

Castanho, P. (2017). Sobre a questão da tarefa no grupo: Aspectos psicanalíticos e psicossociais. Em T. S. Emidio, \& M. Y. (Orgs.), Perspectivas psicanalíticas atuais para o trabalho com familias e grupos na universidade (pp. 87-101). São Paulo: Cultura Acadêmica.

Clark, J., \& Kearns, A. (2012). Housing improvements, perceived housing quality and psychosocial benefits from the home. Housing Studies, 27(7), 915-939. https://doi.org/10.1080/02673037.2012.725829

Conselho Regional de Psicologia de São Paulo. (2019). Apresentação. In. Conselho Regional de Psicologia de São Paulo, Psicologia e moradia: Múltiplos olhares sobre a questão habitacional. São Paulo: Autor.

Desmond, M., \& Gershenson, C. (2016). Housing and employment insecurity among the working poor. Social Problems, 63(1), 46-67. https://doi. org/10.1093/socpro/spv025

Euzébios Filho, A. (2019). 0 valor imensurável do direito à moradia. In: Conselho Regional de Psicologia de São Paulo. Psicologia e moradia: múltiplos olhares sobre a Questão habitacional. Conselho Regional de Psicologia de São Paulo. São Paulo: CRP SP, 2019, p. 35-43.

Fernandes, D. J. (2016). Direito à moradia: Uma questão para a psicologia social? (Dissertação de Mestrado, Pontifícia Universidade Católica de São Paulo), São Paulo, SP, Brasil. Disponível em: https://tede2.pucsp.br/ handle/handle/17143

Fonseca, F. F., Sena, R. K. R., Santos, R. L. A., Dias, O. V., \& Costa, S. M. (2013). As vulnerabilidades na infância e adolescência e as políticas públicas brasileiras de intervenção. Revista Paulista de Pediatria, 31(2), 258-264. https://doi.org/10.1590/S0103-05822013000200019

Guareschi, N. M. F. (2017). Psicologia e políticas públicas: As práticas profissionais no campo da saúde e da assistência social. Psicologia: (iência e Profissão, 37(2), 253-257. https://doi.org/10.1590/1982-3703003722017

Mishra, A. K., \& Mohanty, P. K. (2017). Urban policy in Asia Pacific countries: A case for inclusionary zoning and housing. Asia-Pacific Journal of Regional Science, 1(1), 191-215. https://doi.org/10.1007/s41685-017-0026-4

Nascimento Neto, P., \& Arreortua, L. S. (2019). Financialization of housing policies in Latin America: A comparative perspective of Brazil and Mexico. Housing Studies. https://doi.org/10.1080/02673037.2019.1680815

Nascimento, J. X. (2016). Políticas Públicas e desigualdade de gênero na sociedade brasileira: Considerações sobre os campos do trabalho, da política e da ciência. Mediações, 21(1), 317-337. D0l: https://dx.doi. org/10.5433/2176-6665.2016v21n1p317

Pasternak, S. (2016). Habitação e saúde. Estudos Avançados, 30(86), 51-66. https://dx.doi.org/10.1590/S0103-40142016.00100004

Pevalin, D. J., Reeves, A., Baker, E., \& Bentley, R. (2017). The impact of persistent poor housing conditions on mental health: A longitudinal population-based study. Preventive Medicine, 105, 304-310. https://doi.org/10.1016/j. ypmed.2017.09.020

Pichon-Rivière (1983/2009). O proceso grupal. (8. ed.). (M. S. Gonçalves, \& M. A. F. Velloso, Trads.). São Paulo: Martins Fontes. (Original publicado em 1983)

Rodrigues, L. P. D., \& Moreira, V. S. (2017). Habitação e políticas públicas: 0 que se tem pesquisado a respeito? Revista Brasileira de Gestão Urbana, 8(2), 167-180. https://doi.org/10.1590/2175-3369.008.002.A001

Rollings, K. A., Wells, N. M., Evans, G. W., Bednarz, A., \& Yang, Y. (2017). Housing and neighborhood physical quality: Children's mental health and motivation. Journal of Environmental Psychology, 50, 17-23. https:// doi.org/10.1016/j.jenvp.2017.01.004
Senra, C. M. G., \& Guzzo, R. S. L. (2012). Assistência social e psicologia: Sobre as tensões e conflitos do psicólogo no cotidiano do serviço público. Psicologia \& Sociedade, 24(2), 293-299. https://doi.org/10.1590/5010271822012000200006

Tatagiba, L., \& Teixeira, A. C. C. (2016). Efeitos combinados dos movimentos de moradia sobre os programas habitacionais autogestionários. Revista de Sociologia e Política, 24(58), 85-102. https://dx.doi.org/10.1590/1678987316245804

Vasconcelos, B. R. T., \& Sampaio, C. R. B. (2018). A produção sociopolítica do sofrimento em uma ocupação urbana. Revista Amazônica, 2(22), 169-186. Disponível em: http://periodicos.ufam.edu.br/amazonica/ article/view/5126 